\title{
Effects of machining parameters on Tool wear progression in End milling of AISI 316
}

\author{
Peter Babatunde Odedeyi ${ }^{*}$, Khaled Abou-El-Hossein ${ }^{2}$, Funso Oyekunle ${ }^{3}$, Adeniyi Kehinde Adeleke ${ }^{4}$ \\ 1,2,3,4 Precision Engineering Laboratory, Mechatronics Department \\ School of Engineering, Nelson Mandela University, \\ Port Elizabeth, South Africa \\ *s215391292@mandela.ac.za, $\underline{\text { s216865093@mandela.ac.za, s221390030@mandela.ac.za }}$
}

\begin{abstract}
High-performance machining of difficult-to-cut stainless steel (AISI 316) demands the wear development and optimization of high-performance tools that can withstand tool load without compromising the surface quality of the components being machined. In this study, we have investigated the effects of cutting parameters on AISI 316 steel using a five-axis digitally Computerized Numerically Controlled (CNC) end milling machine with castor oil as coolant. The study was carried out to evaluate and monitor tool wear progression during end milling of stainless steel. To justify the Tool life viability of a coated carbide tool in end milling application, regression analysis an approach used by evaluating the tool life under optimized cutting conditions were carried out in this study. The effects of Speed (2900, 4050 and 5200) rpm, depth of cuts $(1,2$ and 3$) \mathrm{mm}$ and feed $(0.002,0.006$ and 01$) \mathrm{m} / \mathrm{min}$ were analyzed. Tool wear value of $0.174 \mathrm{~mm}$ was achieved through optimization at low values of feed, speed and depth of cut. At low-speed 2900rpm, high feed $0.1 \mathrm{~m} / \mathrm{min}$ and moderate depth of cut of $2 \mathrm{~mm}$, very low tool wear and lasting insert can be achieved.
\end{abstract}

\section{Keywords- component; Tool wear; machining; stainless steel; tool life; flank wear}

\section{INTRODUCTION}

Tool wear is a complex phenomenon because of the complexity of the machine system, generally, it reduces surface quality, increases power consumption, and causes rejection of machined parts. It has a direct effect on the quality of surface finish for any given workpiece, dimensional precision and ultimately the cost of the parts produced.

According to Krolczyk et al, [1] in their study to determine the coated carbides tool life and the tool point surface topography. They discovered that the cutting conditions in the process of turning duplex stainless steel (DSS), and detailed identification of wear mechanisms occurring on the rake face and majorly flank wear. Liu et al, [2] in their study presented how tool nose radius affects the residual stress distribution significantly. They further examined that as the tool wear increased, the residual stress at the machined surface shifted to tensile stress range and the residual compressive stress beneath the machined surface increased greatly. They use the following cutting parameters: Cutting speed $120 \mathrm{~m} / \mathrm{min}$, Feed speed: 0.1 $\mathrm{mm} / \mathrm{rev}$, Depth of cut: $0.1,0.2 \mathrm{~mm}$.

They observed that tool nose radius affected the residual stress at the machined surface significantly at the early cutting stage. The residual stresses at the machined surface shifted to the tensile range with the increase of the tool nose radius. It was concluded that the effect of the nose radius on the residual stress distribution decreased greatly with the increase of the tool wear [2]. Reddy et al. carried out a machining study on AISI 1040 steel by applying cryogenic treatment to P-40 tungsten carbide tools. He found that deep cryogenic treatment enhanced the electrical conductivity of the carbide tools.

The increase in thermal conductivity enhanced the heat dissipation capacity of the cutting tool and helped in decreasing the tool tip temperature, resulting in more hot hardness during machining, which led to less tool wear in the deep cryogenic treated tools compared to the untreated tools [3]. Stainless steels are known for their resistance to corrosion. But their machinability is more difficult than the other alloy steels due to reasons such as having low heat conductivity, high BUE tendency and high deformation hardening [4]. Austenitic stainless steels are characterized by a high work hardening rate, low thermal conductivity, and resistance to corrosion [5]. Many attempts have been made to improve the machinability of austenitic stainless steels[6].

It was reported that austenitic stainless steels are difficult to machine [7]. Problems such as poor surface finish and high tool wear are common in machining of austenitic stainless steel [8]. Ihsan et al. [9] carried out turning tests on AISI 304 austenitic stainless steel to determine the optimum machining parameters. The best cutting speed and feed rate were determined according to flank wear, BUE, chip form, surface roughness of the machined samples and machine tool power consumption. It was concluded that the lowest flank wear is observed at a feed 
rate of $0.25 \mathrm{~mm} / \mathrm{rev}$ for all the cutting speeds. Table 1 shows the chemical composition, of AISI 316 used in this research work. Tool insert from Kennametal with catalogue code KC725M was used. This grade insert is a multilayer compose of carbide grade with a TiAIN coating. A high-performance TiAlN-PVDcoated carbide grade for milling steel.

\section{EXPERIMENTAL SETUP}

The research work was carried out on an industrial five-axis Deckel Maho DMU 40 CNC machine. The DMU $40 \mathrm{CNC}$ machine belongs to the set of innovative mono BLOCK series of CNC machining centers produced by Deckel Maho.

The DMU 40 possesses a motor spindle with a speed up to $12000 \mathrm{rpm}$. In this study, a total of 17 machining runs were carried out to evaluate and validate the modelling approach. Three machining parameters were considered, which are Speed (rpm), feed rate $(\mathrm{mm} / \mathrm{min})$ and depth of cut $(\mathrm{mm})$. The three levels of the speeds are L1 $=2900 \mathrm{rpm}, \mathrm{L} 2=4050 \mathrm{rpm}$ and L3 = $5200 \mathrm{rpm}$. The depths of cut are $1 \mathrm{~mm}, 2 \mathrm{~mm}$, and $3 \mathrm{~mm}$, while the feed rates are $0.02 \mathrm{~mm} / \mathrm{min}, 0.06 \mathrm{~mm} / \mathrm{min}$ and $0.1 \mathrm{~mm} / \mathrm{min}$ for L1, L2 and L3 respectively. Regression analyses were performed. Figure 1 shows experimental set up for machining.

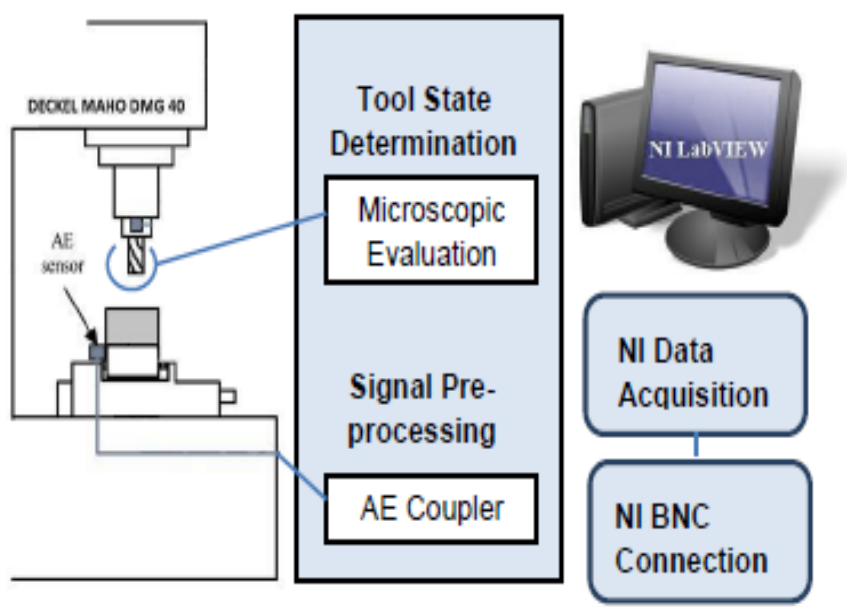

Figure 1: Schematic representation of Experimental setup.

\section{CUTTING TOOL}

The cutting tests were conducted by using a $16 \mathrm{~mm}$ diameter Indexable end-mill with two cutting edges that have 7 degress nose and rake angles. Figure 2 shows a picture of the tool from Kennametal with catalogue number ADPT150516ERHD grade Inserts. Figure 2, is composed of carbide grade with a TiAIN coating. A high-performance TiAlN-PVD-coated carbide grade for milling steel, stainless steel and ductile cast iron. KC725M grade Inserts can be identified with their shapes as highlighted in Figure 2, it is primarily for use in general and heavy machining.

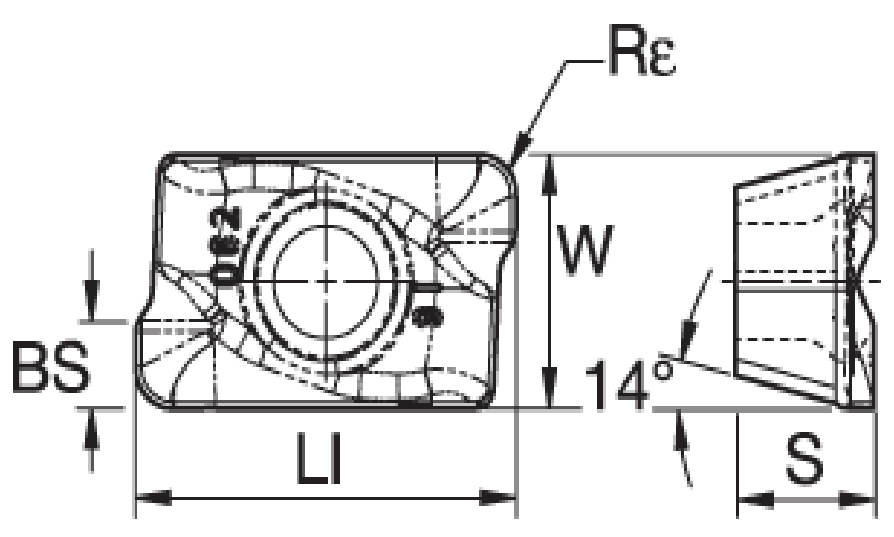

Where:

$\mathrm{Li}=12.06, \mathrm{~S}=3.7, \mathrm{~W}=6.74, \mathrm{Bs}=1.3, \mathrm{Re}=1.19, \mathrm{hm}=0.082$

Figure 2: Indexable tool inserts from Kennametal

Table 1: General Chemical properties of 316 Stainless steel (\%):

\begin{tabular}{ccccccccc}
\hline $\mathbf{C}$ & $\mathbf{M n}$ & $\mathbf{P}$ & $\mathbf{S}$ & $\mathbf{S i}$ & $\mathbf{C r}$ & $\mathbf{N i}$ & $\mathbf{N}$ & $\mathbf{M o}$ \\
& & & & & & & & \\
\hline $0.08 \max$ & $2 \max$ & $0.045 \max$ & $0.03 \max$ & $0.75 \max$ & $16-18$ & $10-14$ & $0.1 \max$ & $2-3$ \\
\hline
\end{tabular}




\section{OPTIMIZATION EFFECT OF DEPTH OF CUT ON TOOL WEAR}

Microsoft Excel was used to carry out profile plot after the regression analysis for optimization as shown in Figure 3, the maximum depth of cut that is needed to have both maximum wear and minimum wear is about $2.3 \mathrm{~mm}$ at various speed and feed combinations. The combined speed and feed for minimum wear are $2900 \mathrm{rpm}$ and $0.1 \mathrm{~mm} / \mathrm{rev}$, the worst case for tool wear can be expected at speed of 5200rpm and feed of $0.1 \mathrm{~mm} / \mathrm{rev}$.

\section{EFFECTS OF FEED AND SPINDLE SPEED ON FLANK WEAR.}

The effects of Feed and spindle speed on the flank wear in Figures 4 and 5 have shown direct impact patterns on the general tool wear of this material.
In Figures $4 \mathrm{a} \& 4 \mathrm{~b}$, at constant feed of $0.02 \mathrm{~mm} / \mathrm{rev}$ regardless of the depth of cut between $1 \mathrm{~mm}$ to $3 \mathrm{~mm}$, it's shown clearly that the higher the speed, the less Flank wear we experienced on the tool. However, opposite is the case in Figures $4 \mathrm{~b}$ and $4 \mathrm{c}$. when the feed rate is increased from 0.06 $\mathrm{mm} / \mathrm{rev}$ to $0.1 \mathrm{~mm} / \mathrm{rev}$. In this case, the higher the speed the faster we experience flank wear rate on the tool respectively. At feed $0.06 \mathrm{~mm} / \mathrm{rev}$, when depth of cut was increased to (2 and 3 ) $\mathrm{mm}$, a huge gap in flank wear was experienced.

However, opposite observations were noticed in the case of Speed variation during machining. In Figure $5 \mathrm{a} \& 5 \mathrm{~b}$, at constant low Spindle speed of 2900rpm and 4050rpm, flank wears were fast noticeable or high on the tool at low feed rates. While at high speed 5200rpm, flank wear increases as feed rates increases.

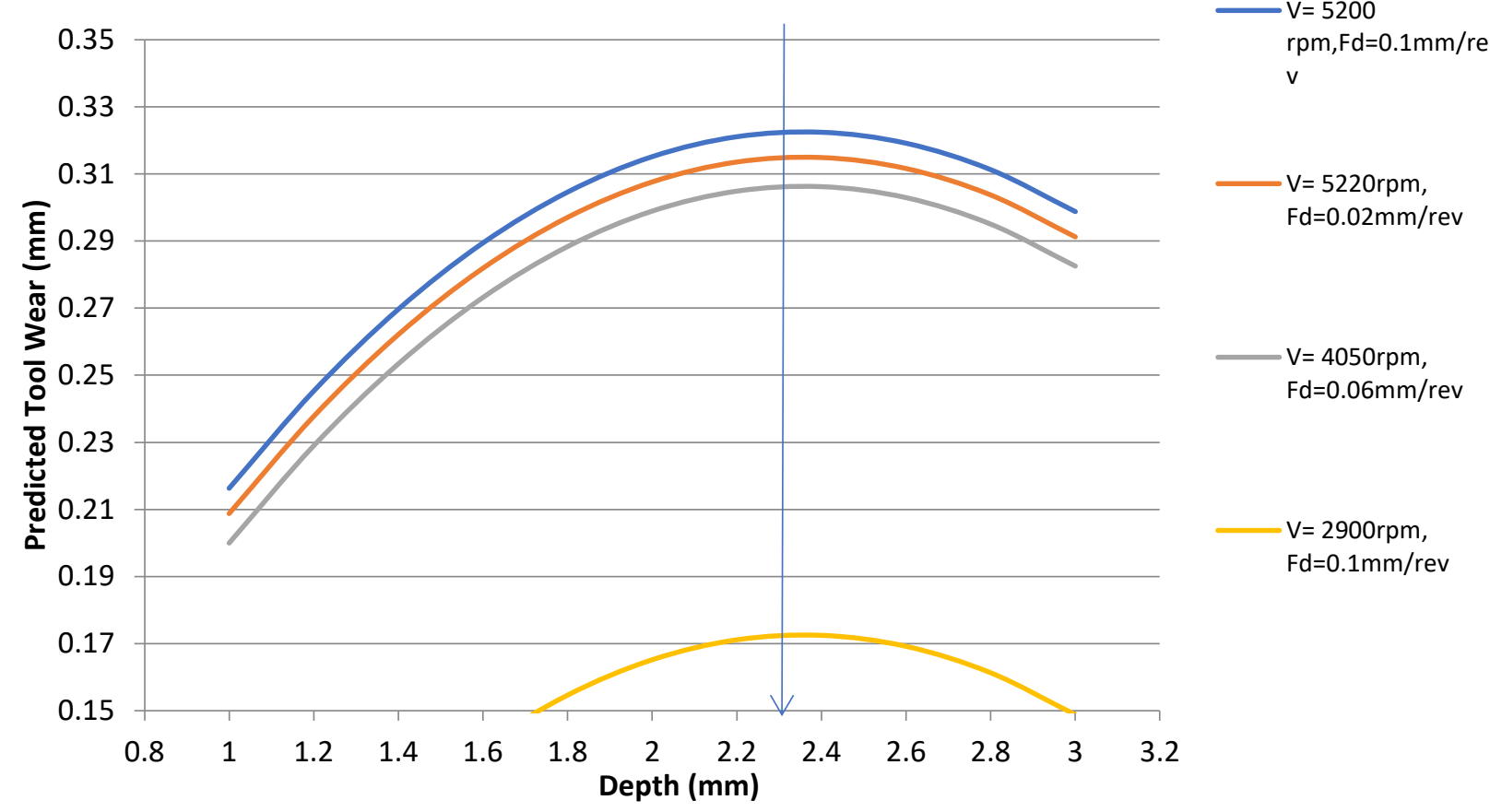

Figure 3: Profile plots for depth of cut 


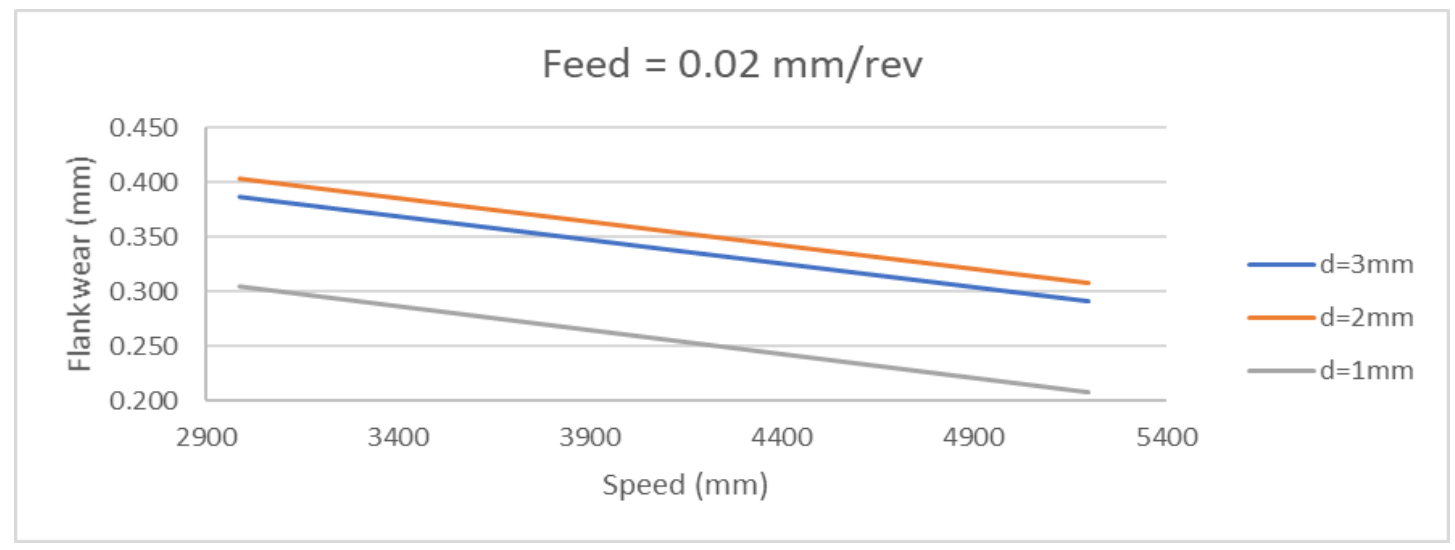

(a)

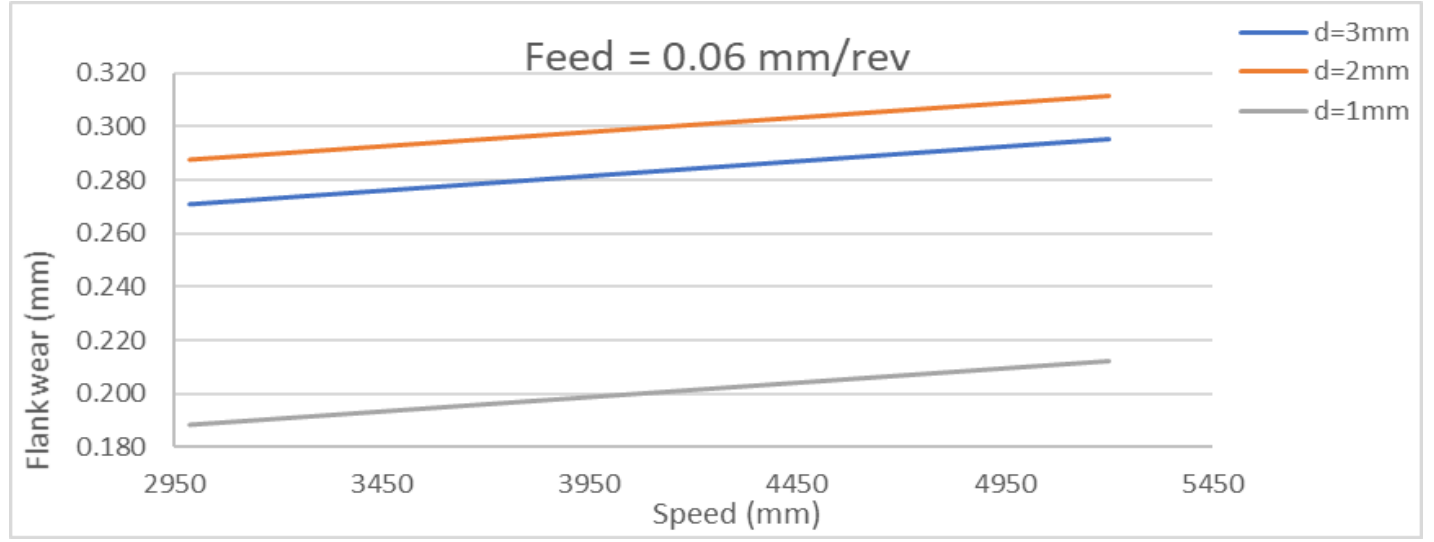

(b)

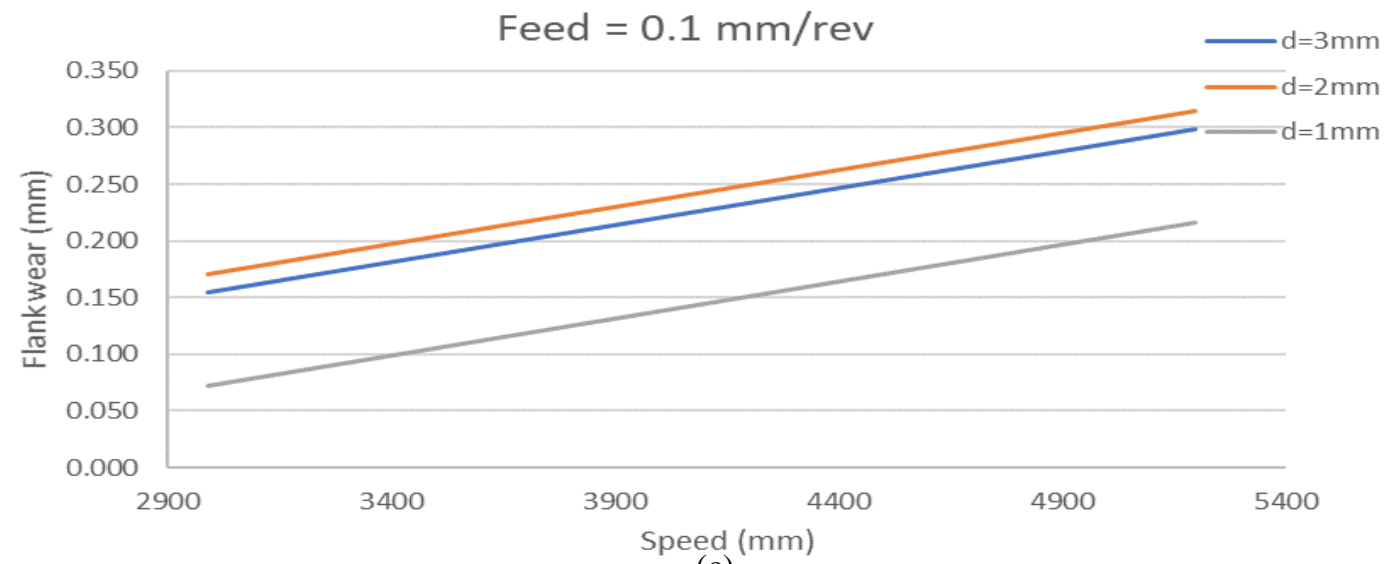

(c)

Figure 4. Effects of Feed rates on Tool wear of AISI 316 


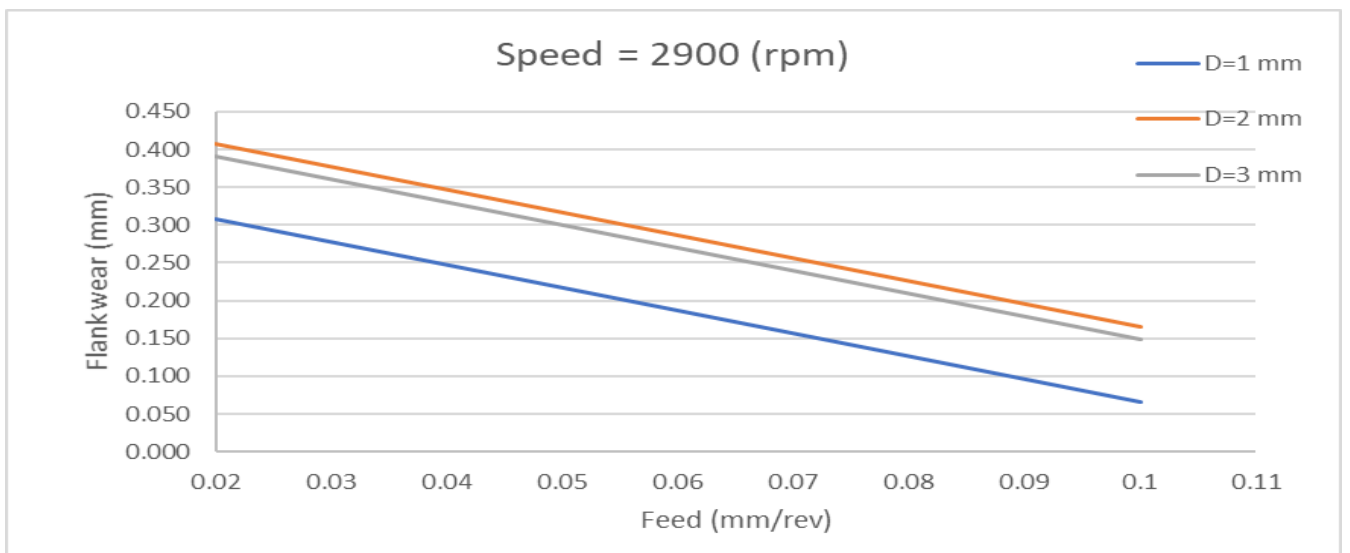

(a)

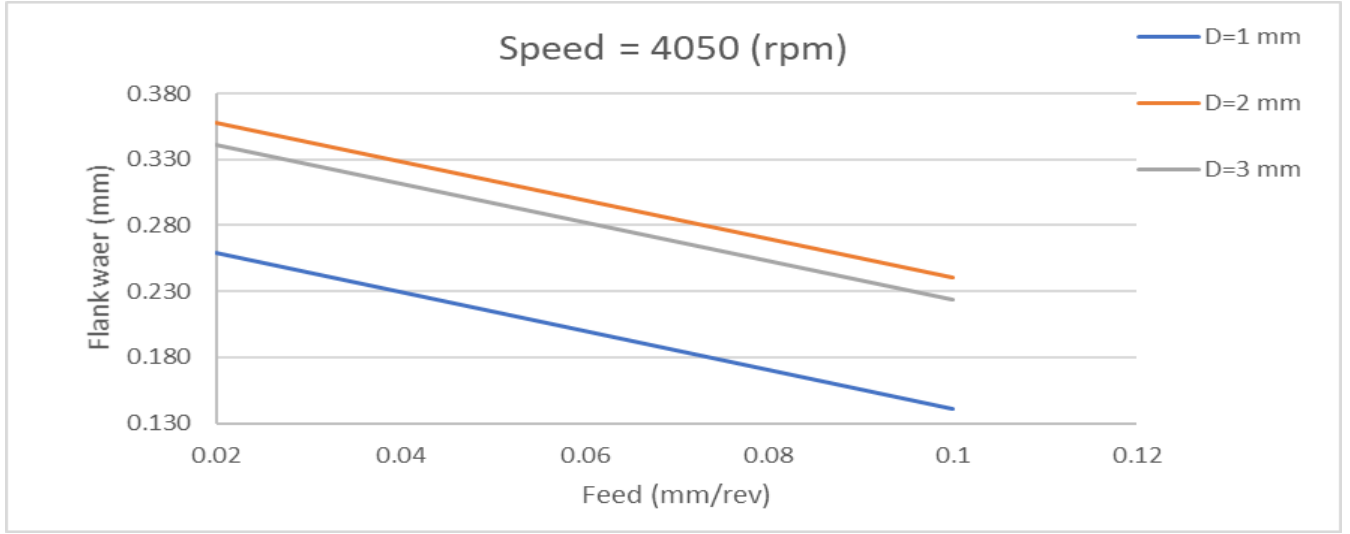

(b)

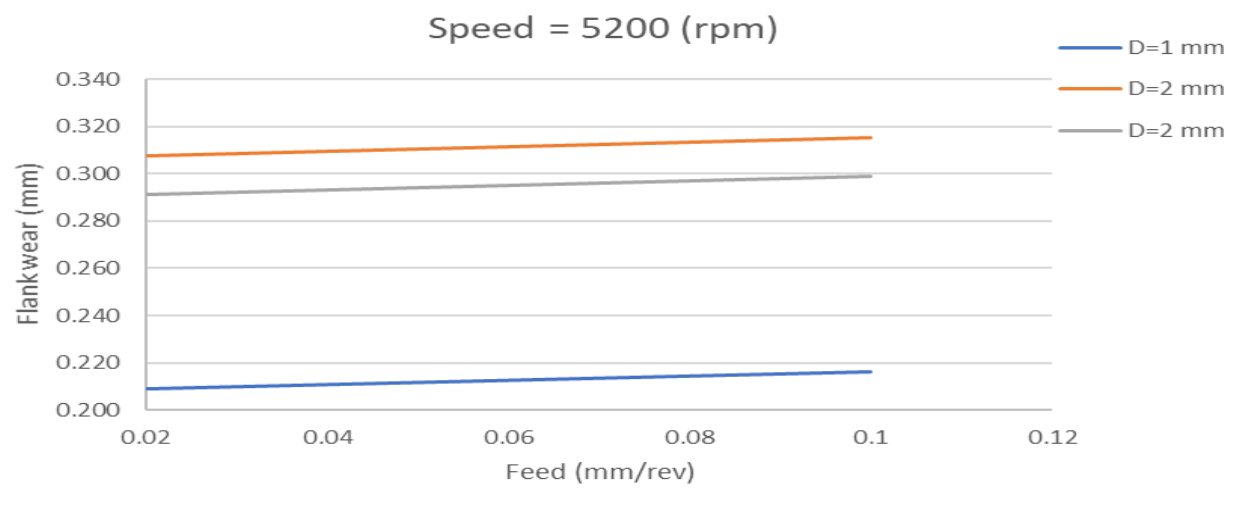

(c)

Figure 5: Effects of Speed on Tool wear of AIS1 316 


\section{ANALYSIS OF TOOL WEAR PROGRESSION}

Figures $6,7 \& 8$. shows the relationships between cutting lengths and the flank wear at different cutting speeds of 146 , 261 and $204 \mathrm{~m} / \mathrm{min}$ and feeds $0.02,0.06$ and $0.1 \mathrm{~mm} / \mathrm{rev}$ respectively. The cutting process was stopped every $200 \mathrm{~mm}$ and the flank wear, $\mathrm{Vb}$ was measured using image analyzers (ZEISS and Olympus Microscopes). The tests were conducted until each tool was considered worn out, $\mathrm{Vb}$ above $0.2-0.4$. However, the ISO standard says once the flank wear exceeds $0.3 \mathrm{~mm}$, the tool is considered worn out.

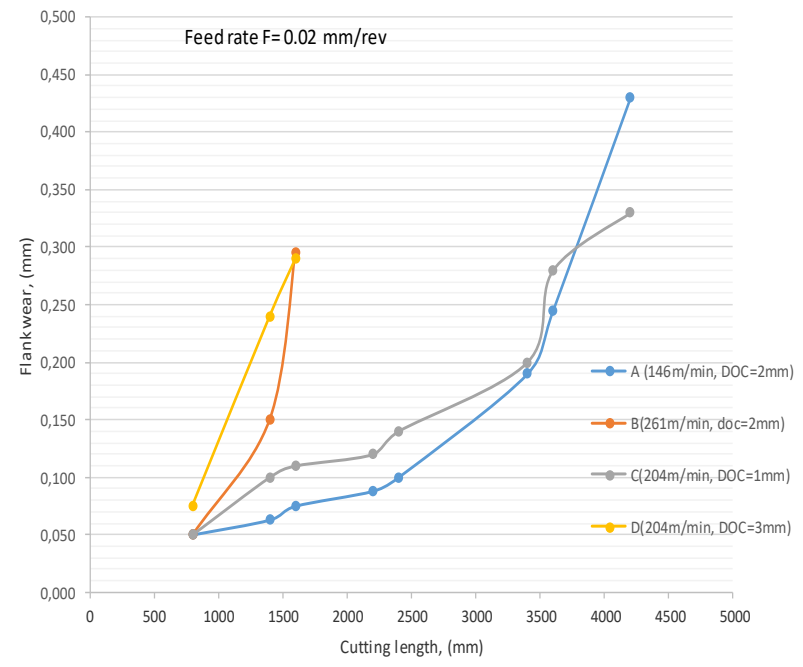

Figure 6: cutting length versus Flank wear at Feed $=0.02 \mathrm{~mm} / \mathrm{rev}$
Considering Figures $6,7 \& 8$, it can be noticed that, for most cutting experiments, the flank wear developed in three stages: rapid initial, gradual uniform and accelerating wear.

Looking at figure 6, it can be seen that at feed $0.02 \mathrm{~mm} / \mathrm{rev}$, for cutting speeds 146, 261 and $204 \mathrm{~m} / \mathrm{min}$ with depth of cuts $2 \mathrm{~mm}$ and $1 \mathrm{~mm}$ respectively all started their initial flank wear at $0.05 \mathrm{~mm}$ but surprisingly, cutting speed with $204 \mathrm{~m} / \mathrm{min}$ and depth of cut $3 \mathrm{~mm}$ demonstrated a different and higher initial flank wear at a very short cutting length.

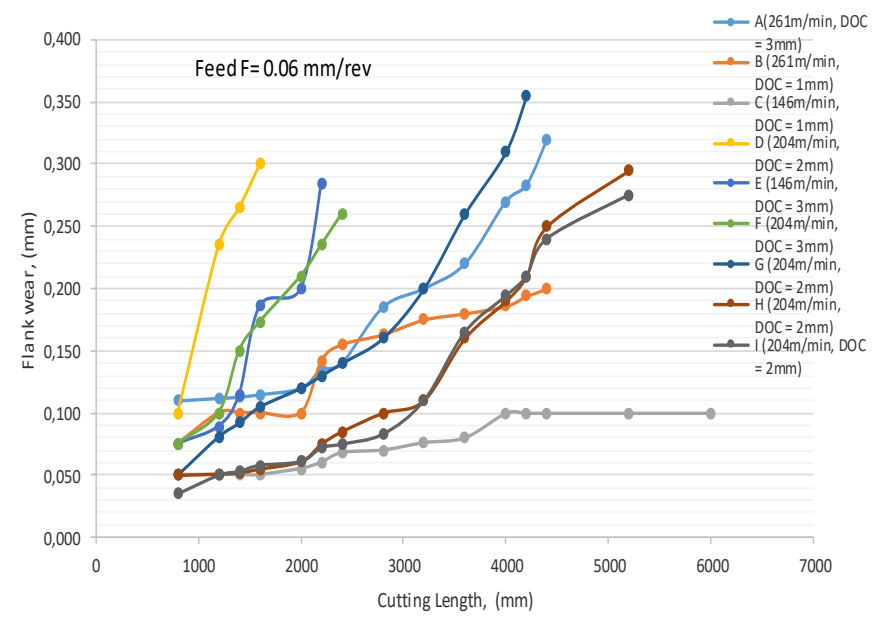

Figure 7: cutting length versus Flank wear at Feed $=0.06 \mathrm{~mm} / \mathrm{rev}$

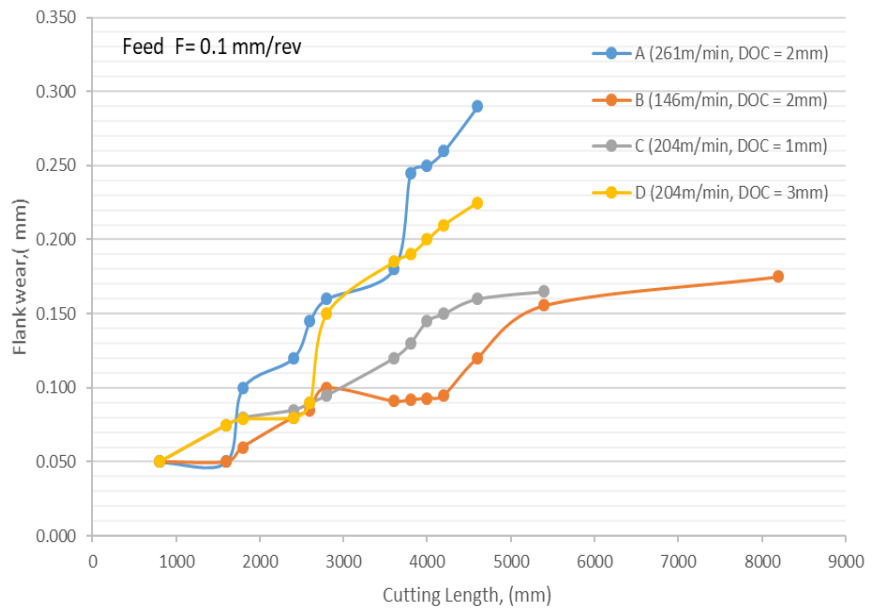

Figure 8: cutting length versus Flank wear at Feed $=0.1 \mathrm{~mm} / \mathrm{rev}$ 
This indicates the effects of depth of cut on tools when machining hard material stainless steel. In all the three Figures $6,7 \& 8$, high depth of cut has shown its effects on cutting length of a tool. From Figure 8, it appears that a high feed rate of $0.1 \mathrm{~mm} / \mathrm{rev}$, low speed of $146 \mathrm{~m} / \mathrm{min}$ and a depth of cut $2 \mathrm{~mm}$ can enhance cutting length.

\section{CONCLUSION}

This present work emphasis on analysis of flank wear in end milling of Austenitic AISI 316 grade stainless steel using coated carbide insert from Kennametal. The subsequent conclusions are drawn. At a high feed, low speed and cutting depth, Tool wear can be improved with an increased cutting length. At low cutting speed and feed, tool life can be improved.

\section{ACKNOWLEDGMENT}

We would like to acknowledge the support of the National Research Foundation (NRF) of South Africa and the Research Capacity Development, Nelson Mandela University for the generous financial support provided.

\section{REFERENCES}

[1] G. Krolczyk, P. Nieslon, S. Legutko. "Determination of tool life and research wear during duplex stainless-steel turning," Archives of Civil and Mechanical Engineering, vol. 15, pp. 347-354, 2015.

[2] M. Liu, J. Takagi, A. Tsukuda. "Effect of tool nose radius and tool wear on residual stress distribution in hard turning of bearing steel," Journal of Materials Processing Technology, vol. 150, pp. 234-241, 2004.

[3] T S. Reddy, T. Sornakumar, M V. Reddy, R. Venkatram, A. Senthilkumar. "Turning studies of deep cryogenic treated p-40 tungsten carbide cutting tool inserts-Technical communication," Machining Science and Technology, vol. 13, pp. 269-281, 2009.

[4] J. Kopač, S. Šali. "Tool wear monitoring during the turning process," Journal of Materials Processing Technology, vol. 113, pp. 312-316, 2001.

[5] M P. Grover, M P. Groover. "Fundamentals of modern manufacturing," ed: John Wiley \& Sons, 1996.

[6] D. O'Sullivan, M. Cotterell. "Machinability of austenitic stainless steel SS303," Journal of Materials Processing Technology, vol. 124, pp. 153$159,2002$.

[7] T. Akasawa, H. Sakurai, M. Nakamura, T. Tanaka, K. Takano. "Effects of free-cutting additives on the machinability of austenitic stainless steels," Journal of Materials Processing Technology, vol. 143, pp. 66-71, 2003.

[8] T. Kosa, R. Ney. "Machining of stainless steels," ASM Handbook., vol. 16, pp. 681-707, 1989.

[9] I. Korkut, M. Kasap, I. Ciftci, U. Seker. "Determination of optimum cutting parameters during machining of AISI 304 austenitic stainless steel," Materials \& Design, vol. 25, pp. 303-305, 2004. 